\title{
LIQUID METAL FLOW CONTROL BY DC ELECTROMAGNETIC PUMPS
}

\begin{abstract}
E. M. Borges,
F. A. Braz Filho,

and L. N. F. Guimarães

Centro Técnico Aeroespacial - CTA

Instituto de Estudos Avançados - IEAv

Divisão de Energia Nuclear - ENU

CP. 6044, CEP. 12231-970

São José dos Campos, São Paulo, Brazil

eduardo@ieav.cta.br

fbraz@iaev.cta.br

guimarae@ieav.cta.br

ABSTRACT

The cooling system of high-density thermal power requires fluids of high thermal conductivity, such as liquid metals. Electromagnetic pumps can be used to liquid metal fluid flow control in cooling circuits. The operation of electromagnetic pumps used to flow control is based on Lorentz force. This force can be achieved by magnetic field and electric current interaction, controlled by external independent power supplies. This work presents the electromagnetic pump operational principles, the IEAv development scheme and the BEMC-1 simulation code. The theoretical results of BEMC-1 simulation are compared to electromagnetic pump operation experimental data, validating the BEMC-1 code. This code is used to evaluate the DC electromagnetic pump performance applied to Mercury flow control and others liquid metal such as Sodium, Lead and Bismuth, used in nuclear fast reactors.
\end{abstract}

Keywords: liquid metal, electromagnetic pump, fluid flow control.

\section{NOMENCLATURE}

$\begin{array}{ll}\text { a } & \text { channel height, } \mathrm{m} \\ \mathrm{b} & \text { channel width, } \mathrm{m} \\ \mathrm{B} & \text { magnetic field, } \mathrm{Wb} / \mathrm{m}^{2} \text { or } \mathrm{T} \\ \mathrm{c} & \text { useful length, } \mathrm{m} \\ \mathrm{d} & \text { iron-break, } \mathrm{m} \\ \mathrm{E}_{\mathrm{c}} & \text { electro-countermove force, } \mathrm{V} \\ \mathrm{F} & \text { force, } \mathrm{N} \\ \mathrm{I} & \text { electric current, } \mathrm{A} \\ \mathrm{I}_{\text {field }} & \text { field current, } \mathrm{A} \\ \mathrm{N} & \text { number of spires } \\ \mathrm{P} & \text { pressure, } \mathrm{N} / \mathrm{m}^{2} \text { or } \mathrm{cm} \mathrm{Hg} \\ \mathrm{R} & \text { electric resistance, } \mathrm{Ohm} \\ \mathrm{T} & \text { temperature, }{ }^{\circ} \mathrm{C} \text { or } \mathrm{K} \\ \mathrm{V} & \text { electric tension, } \mathrm{V} \\ \mathrm{W} & \text { volumetric flow rate }, 1 / \mathrm{s}\end{array}$

\section{Greek symbols}

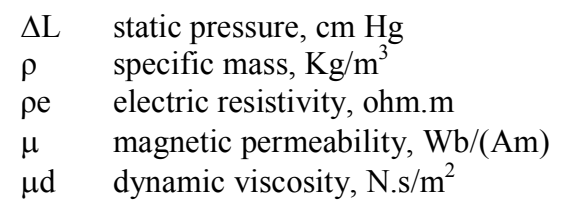

\section{Subscripts}

$\begin{array}{ll}\text { b } & \text { bypass } \\ \text { cal } & \text { calculated } \\ \text { e } & \text { useful } \\ \text { mea } & \text { measured } \\ \text { t } & \text { total } \\ \text { w } & \text { wall }\end{array}$

\section{INTRODUCTION}

The electromagnetic pump research at the Institute for Advanced Studies aims to the development of cooling systems that uses liquid metals as working fluid, because of its capacity of removing high values of thermal power, such as the one that occurs in fast nuclear reactors.

The first two direct current electromagnetic (DC EM) pumps were developed with success. The first one uses a $\mathrm{C}$ magnet and coils, and the second one uses permanent samarium-cobalt magnets for the field generation, as in (Borges, et al., 1995 and Borges, et al., 1996). Both worked quite satisfactory over magnetic field, static pressure and dynamic operation range. The last two requirements were performed on a closed mercury loop especially designed to that end.

The electromagnetic pump works with the Faraday principle, where the electric current and the magnetic field interaction generate the magnetic driving force that produces the metallic fluid flow. No moving parts and totally sealed leads to high reliability. This type of equipment can control a high conductivity liquid metal flow in a closed circuit and facilitate natural circulation in the event of failures or accidents, which is highly convenient for the safety of nuclear reactors. These facts are the reasons for their common use in liquid metal cooled nuclear fast reactors, such as the EBR-II (Lentz, et al., 1985), the SAFR (Lancet and Marchaterre, 1985), the PRISM (Kwant, et al., 1988) and the REARA (Prati, et al., 1994), all these reactors are liquid Sodium cooled. 
Fast reactors cooled by Lead, Bismuth and other liquid metals are being designed using advanced safety concepts (Myasnikov, et al., 1993, Santos and Nascimento, 2002).

The advantage in the use of the electromagnetic pumps on the reactor primary cooling fluid mechanisms comes from a lower pressure loss when compared with the use of centrifugal pumps. That is a result of the fact that the electromagnetic pumps have no moving parts which mean no obstruction to the flow and are the reason for the lower pressure loss and also the fact that they allow flow reversal in case of accidents. The coupling of all these translates into inherent and passive safety used on the project of the third and fourth generation reactors, such as SAFR, PRISM and others.

The computational program BEMC-1 was created to allow the analysis of each development phase of a direct current electromagnetic pump design and to validate its performance. This program facilitates pump evaluation and allow for corrections of the deviations between calculations and experimental data. The focus of this article is in the use of the BEMC-1 program to design direct current electromagnetic pumps and to evaluate the performance of metallic fluid flow in a closed circuit.

It is important to mention that in the case where the permanent samarium/cobalt magnets are used, they are aligned and next to the pumps' channel in order to minimize the magnetic field losses. This procedure is indicated in the case of the use of mercury as a working fluid, which is liquid at environment temperature. For other liquid metals where there is the necessity of heating and thermal insulation that arrangement might be not recommended if the fluid working temperature reaches the proximity of the magnet Currie temperature. Above Currie temperature the magnets will loose its magnetic properties. The $\mathrm{C}$ magnet electromagnetic pump has no limitations regarding temperature. Also, it allows for varying the magnetic field and for the channel thermal insulation. This pump is the choice to test several types of liquid metals and compare its results.

A brief description of the working principles for the EM pumps, through its basic equations is presented in this work. Also some experimental results for DC EM pumps using the $\mathrm{C}$ magnet and coils, with mercury as working fluid are printed in this paper. Some calculation results using the BEMC1 computational program will evaluate the application of DC EM pumps with three liquid metals working fluid: Sodium, Lead and Bismuth.

The simulated results presented in this work concur with the use of EM pumps on the primary and secondary circuits of the advanced and new generation fast reactor cooled with liquid sodium. Also, it concurs with the EM pump use with fast reactors cooled by Lead and Bismuth.

\section{ELECTROMAGNETIC PUMPS}

In a direct current electromagnetic pump the Lorentz force defines the intensity and direction of the force applied on the conductor fluid under the influence of the electric current and the magnetic field. The magnetic field and the main electric current can be controlled by two independent electric power sources.

Figure 1 shows the principle of operation of a DC electromagnetic pump, where $a$ is the channel height of the pump, $\mathrm{m} ; b$ is the channel width, $\mathrm{m}$; and $c$ is the useful length, $\mathrm{m}$.

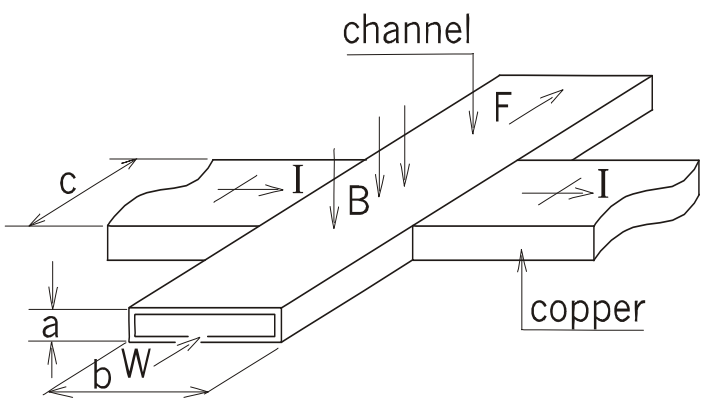

Figure 1. Working principle for a DC EM pump.

\section{Theoretical Model}

With the scheme presented in Figure 1 the DC electromagnetic pumps evaluation equations may be obtained, as presented in (Borges, 1991).

The magnetic field for the $\mathrm{C}$ magnet EM pump is calculated by the Ampere's law, given by the equation:

$$
\mathrm{B}=\mu \mathrm{NI}_{\text {field }} / \mathrm{d}
$$

where, $\mathrm{B}$ is the magnetic induction field intensity, $\mathrm{Wb} / \mathrm{m}^{2}$ or Tesla; $\mu$ is the magnetic permeability, $\mathrm{Wb} /(\mathrm{Am}) ; \mathrm{N}$ is the spire total number of the coils; $\mathrm{I}_{\text {field }}$ is the magnetic field current supplied, A; and $\mathrm{d}$ is the iron-break or air gap length, $\mathrm{m}$.

Considering the magnetic field perpendicular to the main electric current and the direction of the fluid flow, the force resulting from the interaction between magnetic field and main electric current is:

$$
\mathrm{F}=\mathrm{BI}_{\mathrm{e}} \mathrm{b}
$$

where, $\mathrm{F}$ is the force, $\mathrm{N}$; and $\mathrm{I}_{\mathrm{e}}$ is the useful electric current, A.

The pump head can be defined by:

$$
\mathrm{P}=\mathrm{F} /(\mathrm{ab})
$$

taking Eq. (2) into Eq. (3) becomes:

$$
\mathrm{P}=\mathrm{BI}_{\mathrm{e}} / \mathrm{a}
$$


where, $\mathrm{P}$ is the pressure, $\mathrm{N} / \mathrm{m}^{2}$, or

$$
\mathrm{P}=\mathrm{B} \mathrm{I}_{\mathrm{e}} /(1360 \mathrm{a})
$$

where, $\mathrm{P}$ is the pressure, $\mathrm{cm} \mathrm{Hg}$.

Figure 2 shows the equivalent electric circuit of a DC electromagnetic pump.

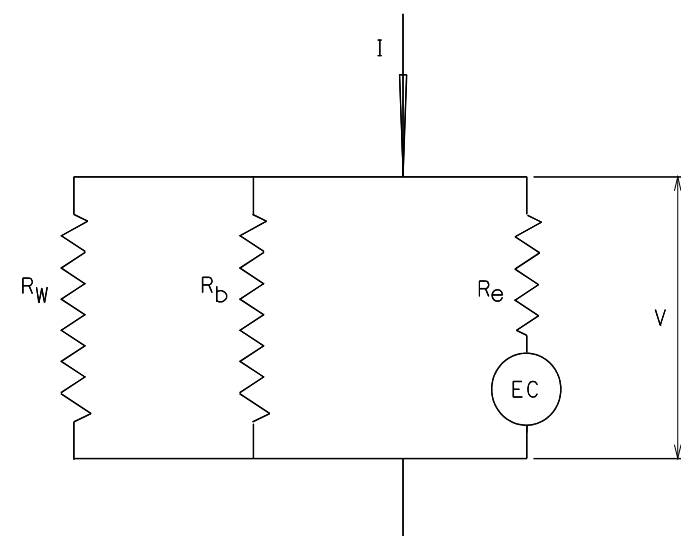

Figure 2. Equivalent electric circuit of DC EM pump.

The electric tension of the electromagnetic pump is calculated by:

$$
\mathrm{V}=\mathrm{I}_{\mathrm{e}} \mathrm{R}_{\mathrm{e}}+\mathrm{E}_{\mathrm{c}}=\mathrm{IR}_{\mathrm{t}}
$$

where, $\mathrm{V}$ is the electric tension, $\mathrm{V} ; \mathrm{R}_{\mathrm{e}}$ is the useful electric resistance (of the fluid in the channel), Ohm; $R_{t}$ is the equivalent electric resistance of the circuit, $\mathrm{Ohm}$; I is the main current, $\mathrm{A}$; and Ec is the electrocountermove force resulting of the fluid moving in the magnetic field, V. This induced voltage can be obtained by:

$$
\mathrm{E}_{\mathrm{c}}=\mathrm{BW} / \mathrm{a}
$$

where, $\mathrm{W}$ is the volumetric fluid flow rate, $1 / \mathrm{s}$.

The useful electric current can be calculated by Eq. (8):

$$
I_{e}=\frac{I}{1+R_{e}\left(\frac{R_{w}+R_{b}}{R_{w} R_{b}}\right)}-\frac{E_{c}}{R_{e}+\frac{R_{w} R_{b}}{R_{w}+R_{b}}}
$$

where, $R_{b}$ is the electric resistance of the bypass or escape, Ohm. This is related with the geometry of the pump, and it is calculated multiplying the useful electric resistance by an empiric correction factor (Watt, 1958). Hence, the useful electric current is a function of the volumetric fluid flow. In the static pressure case (without fluid flow) the last term of the Eq. (8) is equal to zero. And in the dynamic pressure case (with fluid flow) this term is significant and not null.

\section{Calculation Methodology}

The fundamental stages of the design of an electromagnetic pump are the evaluation of magnetic field, static pressure and dynamic fluid flow data.

The BEMC-1 computer program (Borges, et al., 2003) was developed in $\mathrm{C}++$ language. It was created with the objective to evaluate each stage of the development of a DC electromagnetic pump. With this program it is possible to produce variations in all of the important parameters of the pump which helps the design process.

Figure 3 shows the block diagram used for the calculation scheme in the BEMC-1 program. Note the $\mathrm{i}$ index allows the parameters evaluations.

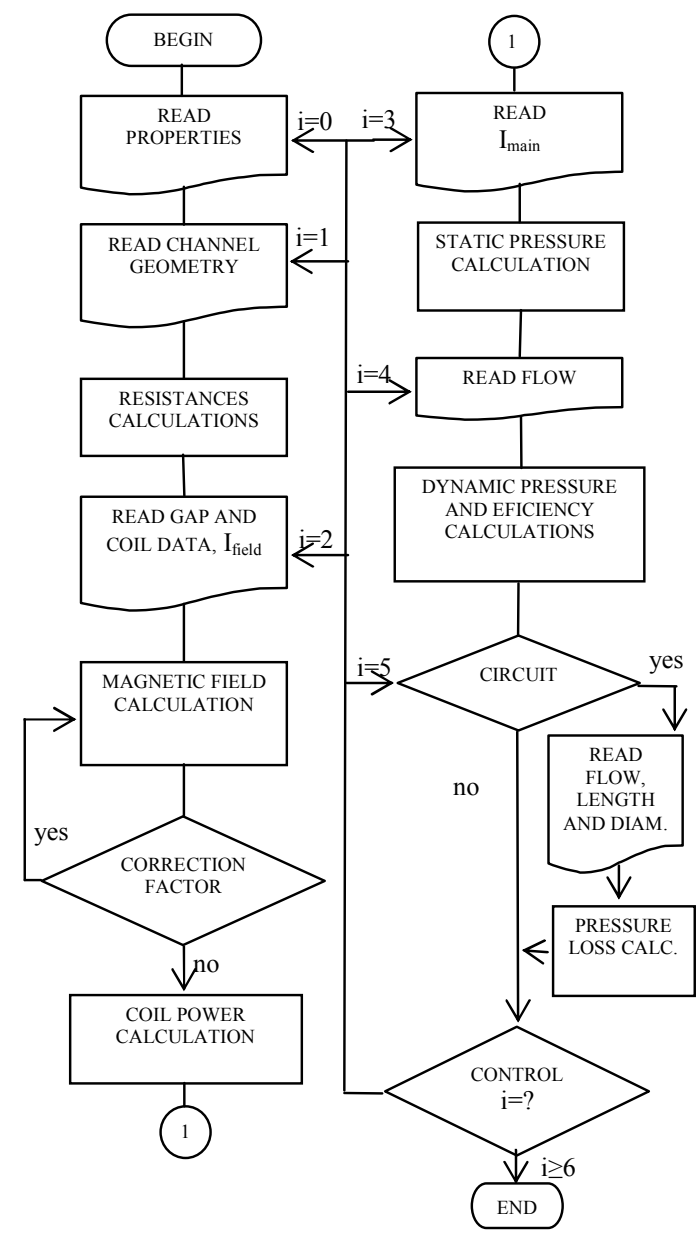

Figure 3. Block diagram for the BEMC-1 program.

Once the liquid metal is chosen and properties are defined, such as, geometry and material of the pump channel, the electric resistances are calculated with Eqs. (6) and (8).

An important parameter is the magnetic field, which is calculated through Eq. (1), as a function of the gap length and the field current, corrected by the proper factor. 
The static pressure, which is a pump operational limit for no flow, is calculated by Eqs. (4) and (5), and depends from the magnetic field and electric current that comes out equation Eq. (8). For this case it is considered the electric resistances, the main current and the fact that the last term of Eq. (8) is zero.

The dynamic pressure given by the pump also can be obtained by Eqs. (4) and (5). In this case the electric current must be calculated with Eq. (8), considering all its terms.

The BEMC-1 program evaluates flow and dynamic pressure produced by the pump in closed circuit, the circuit pressure loss is obtained as a function of the volumetric flow rate, channel equivalent diameter and length.

\section{EVALUATIONS}

The C magnet DC EM pump has a gap width of $20 \mathrm{~mm}$ and a 2000 round coil. Based on the geometry of the $\mathrm{C}$ magnet and the pump channel measurements: channel height, a $10 \mathrm{~mm}$, channel width, b $30 \mathrm{~mm}$, and the useful length, c $70 \mathrm{~mm}$, one may perform experimental measures of magnetic field, static pressure and mercury volumetric flow rate. These measurements are to be compared with modeled results produced with the BEMC-1 program. This comparison validates the program.

Table 1 presents the liquid metal properties that are to be used in this paper: temperature, $\mathrm{T}{ }^{\circ} \mathrm{C}$, electric resistivity, $\rho$ e ohm.m, specific mass, $\rho \mathrm{Kg} / \mathrm{m}^{3}$, and dynamic viscosity, $\mu \mathrm{d} \mathrm{N.s} / \mathrm{m}^{2}$.

Figure 4 presents a scheme for the EM pump.

Table 1. Liquid metal properties simulated.

\begin{tabular}{|c|c|c|c|c|}
\hline metal & Mercury & Sodium & Lead & Bismuth \\
\hline $\mathrm{T}$ & 20 & 500 & 500 & 500 \\
\hline$\rho \mathrm{e}$ & $9.3 \mathrm{e}-7$ & $2.0 \mathrm{e}-7$ & $2.1 \mathrm{e}-7$ & $1.34 \mathrm{e}-6$ \\
\hline$\rho$ & 13400 & 830 & 10470 & 9900 \\
\hline$\mu \mathrm{d}$ & $1.5 \mathrm{e}-3$ & $2.4 \mathrm{e}-4$ & $1.78 \mathrm{e}-3$ & $1.0 \mathrm{e}-4$ \\
\hline
\end{tabular}

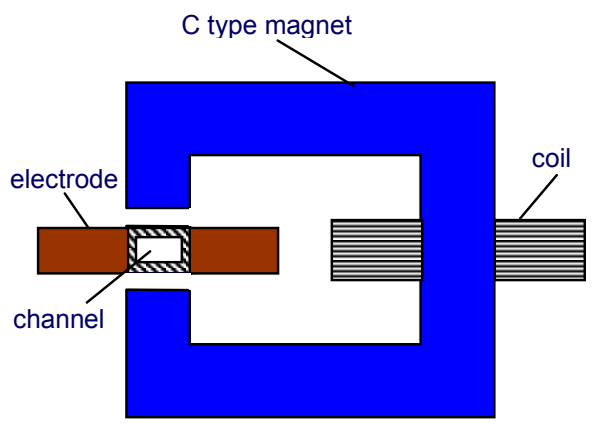

Figure 4. C magnet DC EM pump scheme.

\section{Magnetic Field}

Figure 5 presents the magnetic field curve calculated with BEMC-1, through Eq. (1) and measured values at the center of the GAP in the $\mathrm{C}$ magnet. This curve is a function of the electric current at the coils. The field electric current is generated by a HP-6030A power source, with end scale at $10 \mathrm{~A}$.

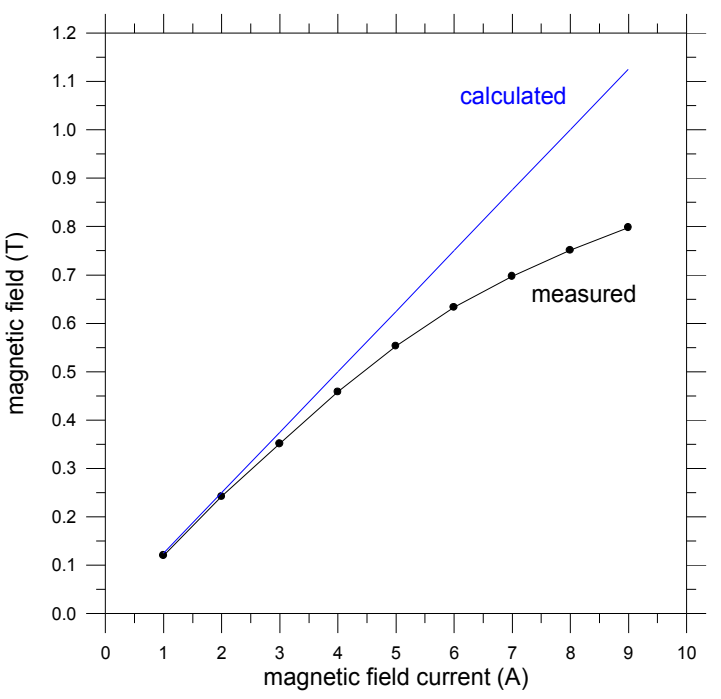

Figure 5. Magnetic field at $\mathrm{C}$ magnet gap center.

For growing field currents the difference between the calculated and the measured values increases, that is due to saturation that occurs at the $\mathrm{C}$ magnet. Therefore, there is the necessity to include proper adjustments in the calculation procedure at the BEMC-1 program. These adjustments are a function of the field current, once the simulated values must reproduce the measured data. The BEMC-1 program allows the direct introduction of the measured magnetic field data.

Table 2 presents the calculated and measure magnetic fields. From this point, on the measured values will be used throughout the rest of the BEMC-1 runs.

Table 2. Calculated and measured magnetic field.

\begin{tabular}{|c|c|c|c|c|c|}
\hline $\mathrm{I}_{\text {field }}(\mathrm{A})$ & 2 & 4 & 6 & 8 & 10 \\
\hline $\mathrm{B}_{\text {cal }}\left(\mathrm{Wb} / \mathrm{m}^{2}\right)$ & 0.25 & 0.5 & 0.75 & 1 & 1.25 \\
\hline $\mathrm{B}_{\text {mea }}\left(\mathrm{Wb} / \mathrm{m}^{2}\right)$ & 0.24 & 0.46 & 0.63 & 0.75 & 0.90 \\
\hline
\end{tabular}

\section{Static Pressure}

In order to measure the gauge pressure on the DC EM pump with no flow it was designed and built a closed parallel circuit. This circuit scheme is presented on Figure 6. It is important to emphasize that this circuit was made of steel and glass pipes in 
order to facilitate observations and measurements. The glass pipes are the vertical ones, which allows for a direct measure in the mercury level difference, $\Delta \mathrm{L} \mathrm{m}$. That difference is the static pressure value.

The static pressure measured values, $\Delta \mathrm{L} \mathrm{m}$, for the EM pump are obtained by varying the magnetic field and the main current value given by a DC power source has an end scale of $800 \mathrm{~A}$.

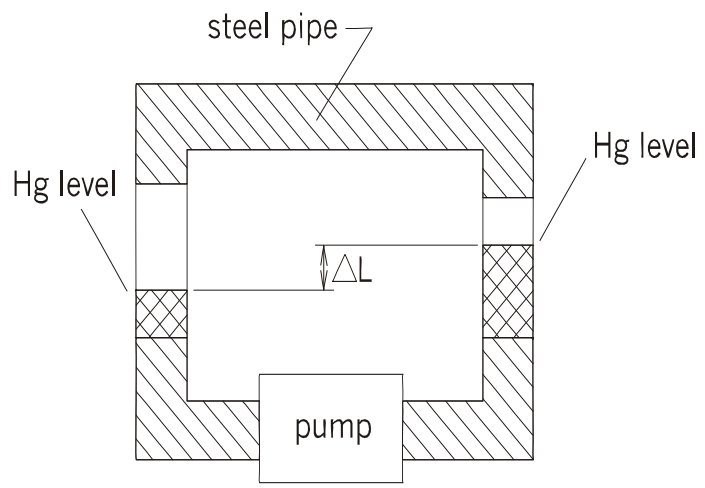

Figure 6. Experimental loop to static pressure mesure.

The calculated static pressure values, produced with the BEMC-1 program, were obtained as a function of the electric current, the pump channel geometry and the measured magnetic field, which took in consideration the $\mathrm{C}$ magnet saturation.

An important parameter for the EM pump calculation is the empirical factor used in the bypass electric resistance calculation. This empirical factor is used in the electric current calculation and depends on the pump geometry, its value was produce according to (Watt, 1958). It is worth to note that the higher is this factor, the lower is electric current loss. Some adjustment in this factor was necessary once it is truly dependent on the particular pump setup at hand.

Eq. (5) is the means by which the static pressure for the EM pump is produced. The electric current $\left(\mathrm{I}_{\mathrm{e}}\right)$ is obtained as a function of the main electric current (I) by Eq. (8), considering, as said previously, its last term zero. Also are used the electric resistivity for the pump structural materials and channel geometric to obtain the electric resistances. Using mercury as working fluid, one gets: $R_{w}=15,010^{-5}$ Ohms and $\mathrm{R}_{\mathrm{e}}=4,010^{-5}$ Ohms. Assuming that $\mathrm{R}_{\mathrm{b}}=5,0$ $\mathrm{R}_{\mathrm{e}}$ the calculation for static pressure can be performed.

Figure 7 presents the comparison between the pump static pressure measured and calculated with BEMC-1 program as explained above. The comparison between measured and calculated static pressure values to the $\mathrm{C}$ magnet DC EM pump, on Figure 7 , shows great agreement and validates the procedures and parameter adjustments made and explained above.

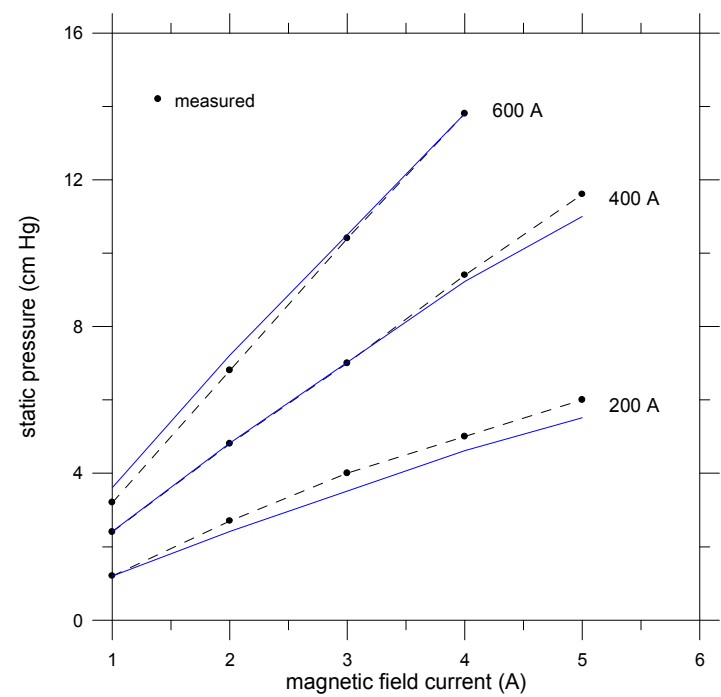

Figure 7. Calculated and measured values for static pressure to DC EM pump.

\section{Volumetric Flow Rate}

For the DC EM pump operation experimental test a steel piping closed loop was built (pipe internal diameter is 0,0122 meters and equivalent length is 3,8 meters). The working fluid used was mercury. A schematic of this circuit is shown in figure 8 , where $\mathrm{P} 1$ and $\mathrm{P} 2$ are pressure gages, FM is the electromagnetic volumetric fluid flow rate meter and DS is the digital measuring system.

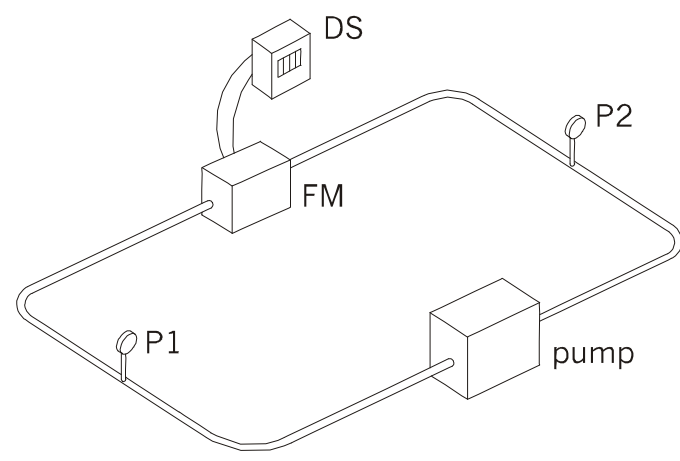

Figure 8. Mercury dynamic loop for DC EM pump testing.

Figure 9 presents the volumetric flow rate from calculated values (BEMC-1) and measured data for the $\mathrm{C}$ magnet DC EM pump. These plotting reveal good agreement between measured data and calculated values. It is worth to emphasize that for the calculated values the electric current, produced with Eq. (8) uses all its terms. 
It is important to mention that the volumetric flow rate depends directly from the field and main electric currents.

There is a clear upper value for the experimental volumetric flow rate of $6[1 / \mathrm{min}]$, this upper limit is associated directly to the limitations imposed by the electric current power sources used to obtain these results.

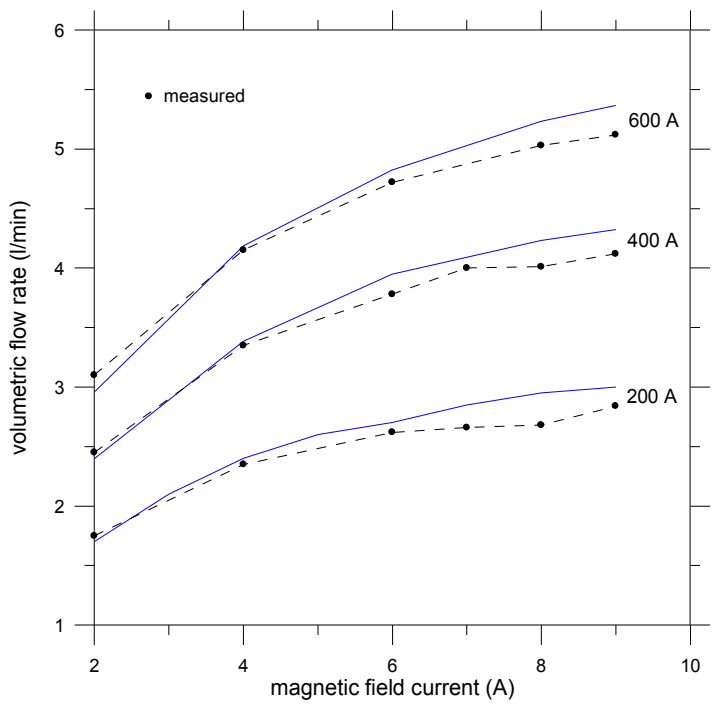

Figure 9. Calculated and measured values of DC EM pump fluid flow rate.

\section{Pump Head}

The good agreement between measured data and calculated values presented on figures 7 and 9 validates the BEMC-1 program calculation procedure, and allow the possibility of producing calculation results with other liquid metals as working fluid, for the designed EM pump.

The DC EM pump calculated performance produce dynamic pressure against volumetric flow plots. These plots takes into account geometrical data, working liquid metal fluid properties (Table 1) and the electric currents involved. These calculations are all realized with the BEMC-1 program. As said before, the EM pump calculated pressure is obtained through Eq. (4). The useful electric current is calculated by Eq. (8), considering all its terms.

The field current for $\mathrm{C}$ magnet DC EM pump is produced by an electric source HP-6030A, with an end scale of $10 \mathrm{~A}$, which generates a maximum magnetic field of $0.90 \mathrm{~Wb} / \mathrm{m}^{2}$, as presented in Table 2. Another electric DC power source, with an end scale of $800 \mathrm{~A}$, produces the main current, which interacts with the magnetic field of the previous source and generates the magnetic force that drives the working fluid.

The BEMC-1 program allows for the obtaining of the pump operation points for a given closed loop.
It produces the dynamic pressure against the volumetric flow rate. These set of plots are called the calculated performance for the $\mathrm{C}$ magnet DC EM pump. It also generates the curve for pressure losses against the volumetric flow for a given closed circuit. The intersection of this curve with previous ones gives the pump operation points.

Figure 10 shows exactly these plots. Note from figure 10 that four sets of operation points are obtained. These points are related with values of magnetic fields and main current and are the main characteristic of the system, or, the association of the pump with the closed loop attached to it. It is important to keep in mind that the results presented on Figure 10 uses mercury as working fluid. Its is also important to notice that the values presented for dynamic pressure are all inferior to the static pressure, given the main current and magnetic field. The calculation procedure of the BEMC-1 program allows for the compatibility guarantee between the dynamic pressure against volumetric flow rate and the pressure loss against volumetric flow curves.

It is interesting to mention that for a mechanic centrifugal pump the dynamic pressure against the volumetric flow rate generates curved plots, due to friction losses increases as rotation or volumetric flow increase. The same does not happen with the dynamic pressure against the volumetric flow rate plot for the EM pump. In this case it generates straight lines. Also the straight lines are not parallel and that is due to the different magnet field for each line. All these features are presented in the plots of Figure 10. Also the maximum value for the pump dynamic pressure increases with the electric current increase. And the dynamic pressure decreases as the volumetric flow rate increases.

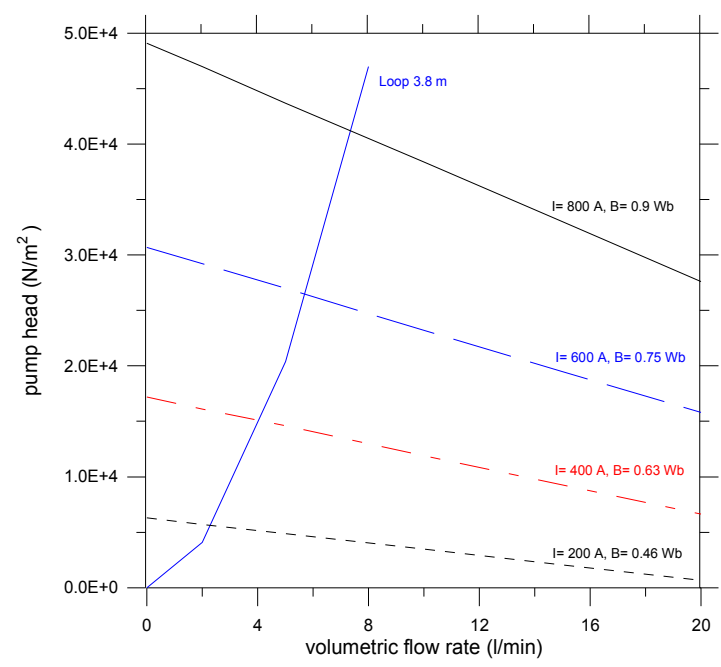

Figure 10. Calculated dynamic performance of the $\mathrm{C}$ magnet DC EM pump with Mercury. 
Figures 11, 12 and 13 presents, respectively, the calculated performance curves for the DC EM pump operating with Sodium Lead and Bismuth. Also it is plotted the pressure loss curve for the specific dynamic closed loop used.

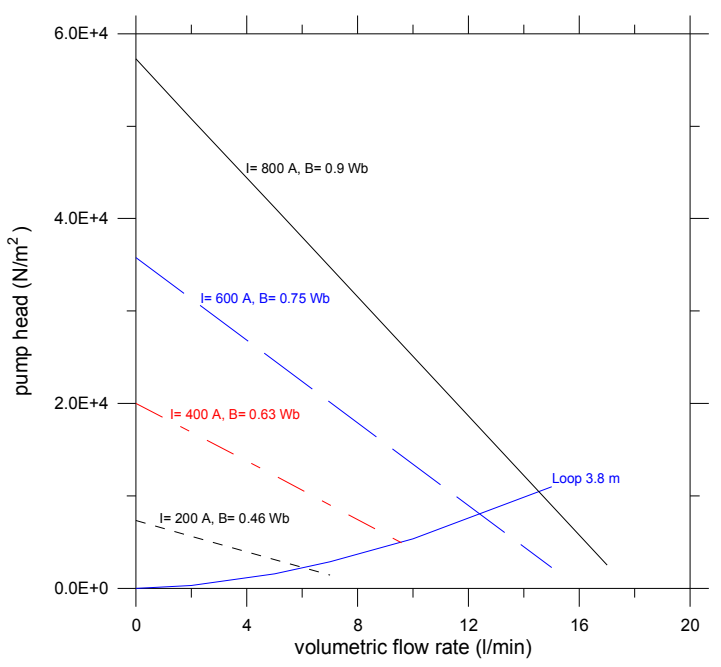

Figure 11. Calculated dynamic performance of the $\mathrm{C}$ magnet DC EM pump with Sodium.

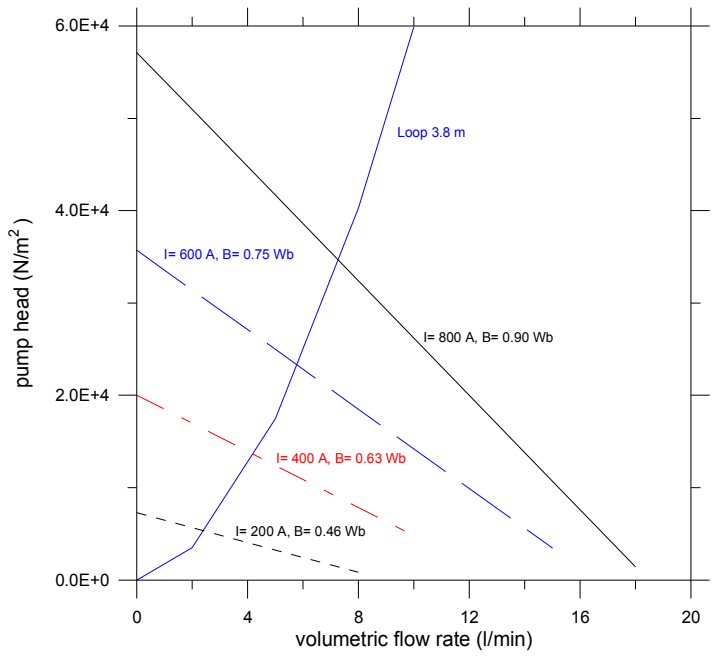

Figure 12. Calculated dynamic performance of the $\mathrm{C}$ magnet DC EM pump with Lead.

Table 3 presents the maximum pump capacity operating points at the dynamic loop for the $\mathrm{C}$ magnet DC EM pump as a function of the available electric sources with maximum main electric current (I) of $800 \mathrm{~A}$ and maximum magnetic field (B) of 0,90 $\mathrm{Wb} / \mathrm{m}^{2}$, for all liquid metals of interest. The parameters are: volumetric flow rate, in $(1 / \mathrm{min})$, and dynamic pressure or pump head, in $\left(\mathrm{N} / \mathrm{m}^{2}\right)$. All these results produced with the $\mathrm{BEMC}-1$ program.

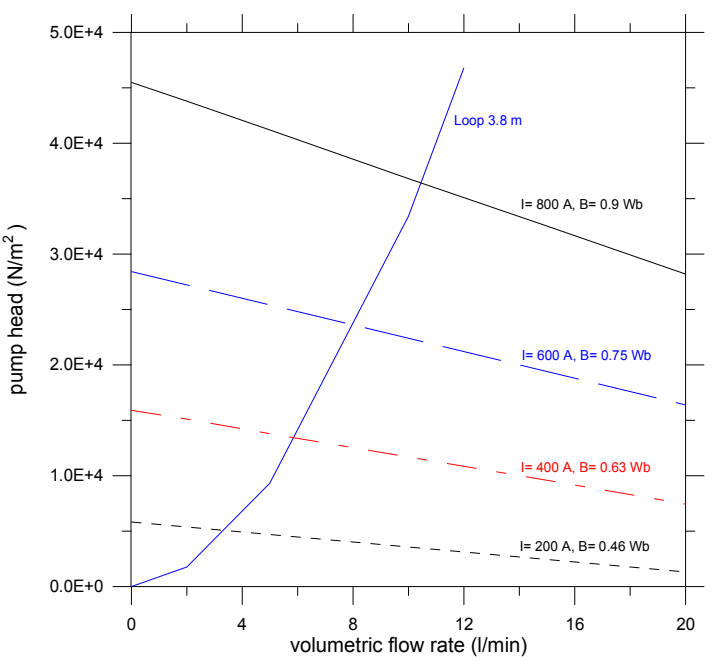

Figure 13. Calculated dynamic performance of the $\mathrm{C}$ magnet DC EM pump with Bismuth.

Table 3. Operation points C magnet DC EM pump at dynamic loop with the liquid metals of interest.

\begin{tabular}{|c|c|c|c|c|}
\hline Metal & Mercury & Sodium & Lead & Bismuth \\
\hline Flow & 7,3 & 14,5 & 7,2 & 10,4 \\
\hline Head & 41200 & 10400 & 34600 & 36500 \\
\hline
\end{tabular}

\section{CONCLUSIONS}

The electromagnetic pump works by Faraday's principle. It does not have moving parts which enhances its reliability. This kind of pump drives the flow of liquid metal or any fluid with high electric conductivity. As it was shown in this paper this kind of pump offer no great resistance to the fluid flow because it has no impellers. This facilitates the natural circulation of the fluid and enhances its safe passivity feature. For that, this kind of pump is desired to be present in the new fast reactor designs.

The BEMC-1 program was built with the capability of variation of several key parameters important in the design of a DC electromagnetic pump. This allows great flexibility to search and find the optimal operation points. The BEMC-1 program, once defined the working fluid and its properties, as well as pump channel geometry and materials, allows for the calculation of all electrical resistances involved. Following the calculation it produces the magnetic field, the static pressure, the volumetric flow rate and the dynamic pressure as a function of the imposed electric currents. The pressure losses are also calculated as a function of the volumetric flow, pipe diameter and its equivalent length.

The BEMC-1 program allows the performance evaluation of EM pump operating with several liquid 
metals of interest. The operating points for each case (different working fluid) were determined through the plotting of the dynamic pressure against the volumetric flow rate and the pressure losses against the volumetric flow rate. For each liquid metal of interest four points were determined. Table 3 presents the maximum operating point values for each liquid metal.

For the mercury the dynamic pressure and the pressure loss for a given volumetric flow rate present the highest value among the liquid metals analyzed in this article. For the bismuth its operation curve is closed to the mercury but with smaller pressure losses. The dynamic pressure curves produced with lead and sodium present very similar derivative, which is due to the proximity of the electric resistivity value for both liquid metals. The pressure losses for the sodium present the smallest values and that is due to the lower values of its specific mass and dynamic viscosity. The previous observation leads to the conclusion that sodium is an easier metal to drive (pump) when compared with the other three metals considered.

As expected, for the same pump project and same conditions the operation point for each liquid metal is different. Also, the BEMC-1 simulation results show the basic reason why sodium has been the most common choice of liquid metal to work as cooling fluid on fast nuclear reactor projects; it is the easier one to pump.

\section{REFERENCES}

Borges, E. M., 1991, Desenvolvimento e Simulação Computacional de Bombas Eletromagnéticas Termoelétricas para o Controle do Escoamento em Reatores Nucleares Espaciais Refrigerados a Metal Líquido, Tese de Doutorado, Instituto Tecnológico de Aeronáutica - ITA, São José dos Campos, SP, Brasil.

Borges, E. M., Sircilli Neto, F., Migliano, A. C., Braz Filho, F. A., Guimarães, L., and Rosa, M., 1995, Ensaios de Pressão Estática de Bomba Eletromagnética de Corrente Contínua, in: XIII Congresso Brasileiro de Engenharia Mecânica, Belo Horizonte, MG, Brasil.

Borges, E. M., Sircilli Neto, F., and Passaro, A., 1996, Rare-Earth Magnets Applied to Liquid Metal Flow, in: XIV International Workshop on Rare-Earth Magnets and Their Applications, Sao Paulo, SP, Brazil.

Borges, E. M., Braz Filho, F. A., Guimarães, L., and Hirdes, V., 2003, Software for DC Electromagnetic Pump Simulation - BEMC-1 In: XVII International Congress of Mechanical Engineering, Sao Paulo, SP, Brazil.

Kwant, W., Dubberley, A. E., Husbedt, A., Nemeth, L. J., Olich, E. E., Patel, M. R., Ramsour, N. L., Fanning, A. W., and Dahl, L. R., 1988, PRISM
Reactor Design and Development. in: International Topical Meeting on Safety of Next Generation Power Reactors, Seattle, USA.

Lancet, R. T., and Marchaterre, J. F., 1985, Inherent Safety of the SAFR Plant. In: Proceedings of the International Topical Meeting on FAST REACTOR SAFETY, Tennessee, USA.

Lentz, G. L., Buschman, H. W., and Smith, R. N., 1985, EBR-II - Twenty Years of Operation Experience, in: Symposium on Fast Breeder Reactors: Experience and Future Trends, Lyon, France.

Myasnikov, V. O., Stekolnikov, V. V., Stepanov, V. S., Gorshkov, V. T., Kulikov, M. L., Shulyndin, V. A., Gromov, B. F., Kalashinikov, A. G., Pashikin, Y. G., Stepanov, V. N., Tosinsky, G. I., and Chekunov, V. V., 1993, Conceptual Design of Module Fast Reactor of Ultimate Safety Cooled by Lead-Bismuth Alloy, Trans. Am. Nucl. Soc., 67, 1, pp. 151, USA.

Prati, A., Menezes, A., Borges, E. M., and Braz Filho, F. A., 1994, Concepção de um Reator Rápido Experimental para o Brasil In: V Congresso Geral de Energia Nuclear, Rio de Janeiro, RJ, Brasil.

Santos, A., and Nascimento, J. A., 2002, An Integral Lead Reactor Concept for Developing Countries, Nuclear Technology, 140, 3, pp. 233 254, USA.

Watt, D. A., 1958, The Design of Electromagnetic Pumps for Liquid Metals, Atomic Energy Research Establishment - AERE R/R 2572, Harvel, Berkshine.

Received: June 20, 2009

Revised: July 20, 2009

Accepted: August 20, 2009 